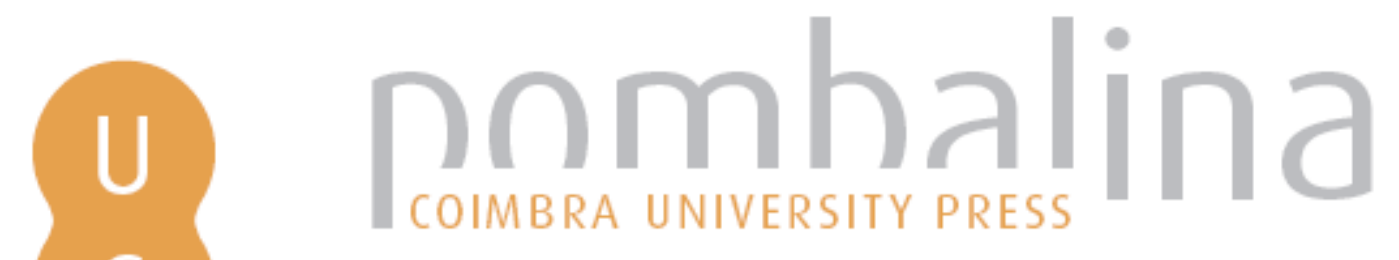

\title{
Da cientificidade e sobrevivência da história na era da informação
}

Autor(es): $\quad$ Silva, Armando Malheiro da

Publicado por: Imprensa da Universidade de Coimbra

URL

persistente: URI:http://hdl.handle.net/10316.2/31576

DOI: $\quad$ DOI:http://dx.doi.org/10.14195/978-989-26-0199-1_5

Accessed : $\quad$ 26-Apr-2023 11:03:34

A navegação consulta e descarregamento dos títulos inseridos nas Bibliotecas Digitais UC Digitalis, UC Pombalina e UC Impactum, pressupõem a aceitação plena e sem reservas dos Termos e Condições de Uso destas Bibliotecas Digitais, disponíveis em https://digitalis.uc.pt/pt-pt/termos.

Conforme exposto nos referidos Termos e Condições de Uso, o descarregamento de títulos de acesso restrito requer uma licença válida de autorização devendo o utilizador aceder ao(s) documento(s) a partir de um endereço de IP da instituição detentora da supramencionada licença.

Ao utilizador é apenas permitido o descarregamento para uso pessoal, pelo que o emprego do(s) título(s) descarregado(s) para outro fim, designadamente comercial, carece de autorização do respetivo autor ou editor da obra.

Na medida em que todas as obras da UC Digitalis se encontram protegidas pelo Código do Direito de Autor e Direitos Conexos e demais legislação aplicável, toda a cópia, parcial ou total, deste documento, nos casos em que é legalmente admitida, deverá conter ou fazer-se acompanhar por este aviso. 
Maria Manuela Tavares Ribeiro

Coordenação

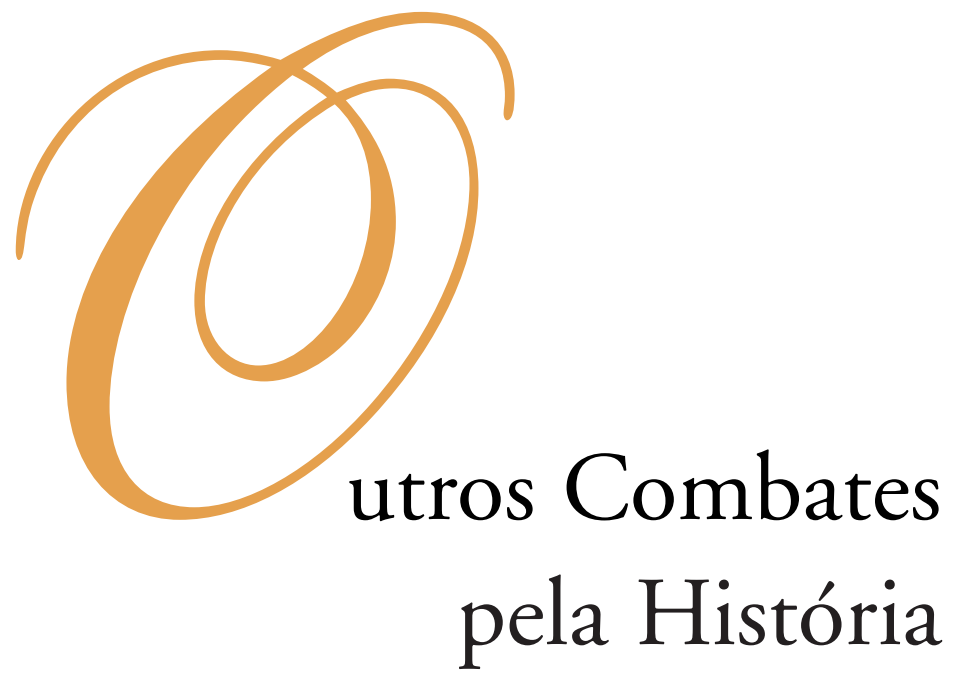




\section{COORDENAÇĀO EDITORIAL}

Imprensa da Universidade de Coimbra

Email: imprensauc@ci.uc.pt

URL: http://www.uc.pt/imprensa_uc

Vendas online: http://livrariadaimprensa.com

\section{CONCEPÇÃO GRÁFICA}

António Barros

\section{ORgANIZAÇĀO DOS TEXTOS}

Isabel Maria Luciano

Marlene Taveira

PRÉ-IMPRESSÃO

António Resende

Imprensa da Universidade de Coimbra

EXECUÇÃO GRÁFICA

SerSilito • Maia

ISBN

978-989-26-0041-3

DEPósito LEGAL

OBRA PUBLICADA COM O APOIO DE:

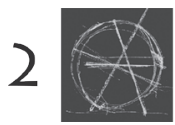

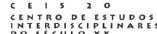

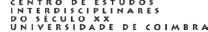

FCT Fundação para a Ciência e a Tecnologia

MINISTÉRIO DA CIÊNCIA, TECNOLOGIA E ENSINO SUPERIOR Portugal

Programa Operacional Ciência, Tecnologia, INOVAÇĀo DO QUADRo COMUNITÁRIO DE APOIO III

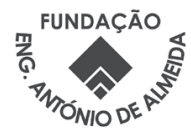

C JULHO 2010, IMPRENSA DA UNIVERSIDADE DE COIMBRA 
Maria Manuela Tavares Ribeiro

Coordenação

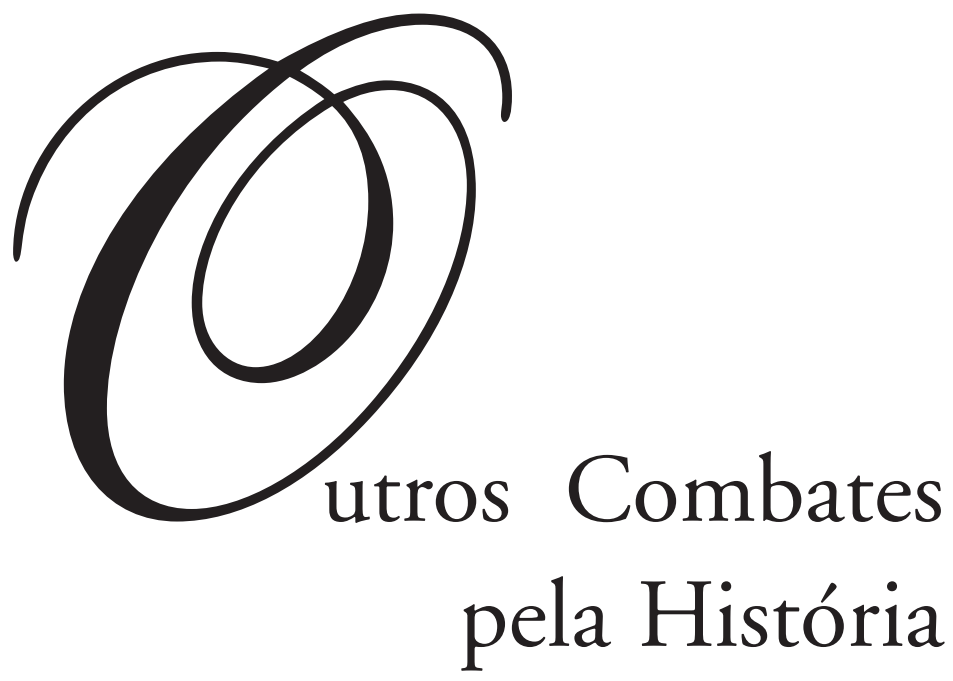

- colmbra 2010 
Outras Teorias da História 


\title{
Armando Malheiro da Silva
}

\section{DA CIENTIFICIDADE E SOBREVIVÊNCIA DA HISTÓRIA NA ERA DA INFORMAÇÃO}

\author{
L'homme vit dans les trois termes du temps. Les souvenirs \\ de son passé, les espérances de son avenir, lui sont aussi inhérens \\ et essentiels que sa realité présent. \\ (Théophile Thoré-Bürger - Dictionnaire de Phrénologie et de \\ Physiognomonie, article Esperance, 1836, p. 141).
}

\section{A escolha do tema}

Não me foi fácil escolher o tema ou, mais precisamente, o problema adequado para partilhar no Colóquio Internacional Outros Combates pela História, concebido e tecido em torno do exemplo maior de historiador (muito versátil ao ponto de ter começado a investigar as ideias políticas na Idade Moderna e se tornou, nas últimas duas décadas, um reconhecido especialista no Estado Novo português), de universitário e de cidadão, que o Professor Luís Reis Torgal, meu Mestre e, sobretudo, meu grande e perene Amigo, é para todos nós, os que o conhecem, seguem, respeitam e admiram.

Não foi fácil, porque não quis (ou não pude...) ir pelo que seria mais previsível e imediato: pegar num texto relacionado com as pesquisas que encetei, sob sua orientação, no campo específico da História das Ideias e da Política portuguesa nos sécs XIX-XX; ou, em alternativa, recorrer ao meu lado de arquivista e de documentalista (faceta evocada, várias vezes, pelo meu Mestre em tom divertidamente crítico...) procurando alertar os Poderes públicos e a comunidade dos historiadores para o estado e a necessidade de preservação dos Arquivos, que continuam a ser perspectivados, inevitavelmente, como laboratórios da História e, sem dúvida, como «espaços concentrados» de documentação indispensável para o refrescamento e a validação da escrita historiográfica. Esta tarefa acabou sendo muito bem cumprida pelo colega brasileiro Caio Boschi, pelo que não me restou outra saída que não fosse arriscar uma reflexão ou, talvez melhor dizendo, uma divagação curta pelo futuro mais ou menos próximo, que a cada dia que passa está a modelar e a inquietar o nosso presente e a adensar o passado, 
objecto fluido da História. Num encontro de historiadores é, certamente, algo exótico aparecer uma voz, ainda que frágil e efémera, a evocar o futuro, mas não é preciso um grande esforço poético ou filosófico para captar a evidência profunda de que o «futuro está prenhe de passado». Logo, não é absurdo que num momento de viragem e de incertezas tão diversas e inquietantes, como o que vivemos, se possa pensar a História, olhando para o que aí vem, ou pode vir, e não para o que já foi...

Decidi, pois, fazer um mix com as facetas de aprendiz de historiador e de militante da Ciência da Informação, que, através da parceria estratégica das Faculdades de Letras e de Engenharia da Universidade do Porto, e, sobretudo, a partir de 2002 está a ser implantada e desenvolvida, formando licenciados e profissionais, e promovendo, em nível de pós-graduação, investigação vital para a identidade e desenvolvimento de um campo disciplinar emergente e fragmentado por ópticas e práticas profissionais antigas e muito vincadas ${ }^{1}$.

As questôes que me animaram e me trouxeram até ao texto, que deponho perante o leitor, são relativamente simples: como poderá a História sobreviver e manter-se como ciência social, dentro dos parâmetros de uma epistemologia desencantada e afastada das premissas positivistas e marxistas, mas, ao mesmo tempo, amparada em critérios metodológicos que visam a «objectividade possível» e a «reconstituição de uma realidade vivida e acontecida" como poderá renovar-se, sem se mudar ou perder na Era da Informação, em que já vivemos, rodeados por desafios novos, surpreendentes e imprevisíveis?

A resposta é, pelo contrário, bastante difícil e sujeita a ficar indefinidamente incompleta. Não ouso, aqui, algo mais que um esboço incipiente.

\section{A «Galáxia Internet» ou a gestação actual do passado histórico}

Para ensaiar um esboço reflexivo de resposta, começo por me valer de um autor, que não é historiador mas sociólogo e que nos legou um trabalho sólido de análise prospectiva sobre a «Sociedade em Rede», iniciada no pós-II Guerra Mundial e derivada, entre outros factores decisivos, do clima armamentista, ideológico e técnico-científico da Guerra Fria (1945-1989). Refiro-me a Manuel Castells, autor da trilogia A Era da Informação: economia, sociedade e cultura ${ }^{2}$ e do livro-súmula $A$ Galáxia Internet ${ }^{3}$, além de uma longa e esclarecedora entrevista, vertida em formato livro, com Martin

\footnotetext{
${ }^{1}$ SILVA, Armando Malheiro da; RIBEIRO, Fernanda - Das «ciências» documentais à ciência da informação: ensaio epistemológico para um novo modelo curricular. Porto: Edições Afrontamento, 2002; e SiLVA, Armando Malheiro da - A Informação: da compreensão do fenômeno e construção do objecto científico. Porto: Cetac. Media/Edições Afrontamento, 2006.

2 CASTELls, Manuel - A Era da informação: economia, sociedade e cultura. Vol. 1 - A Sociedade em rede; vol. 2 - O Poder da identidade; e vol. 3 - O Fim do milênio.Lisboa: Serviço de Educação e Bolas/Fundação Calouste Gulbenkian, 2002-2003.

3 CASTELLS, Manuel - A Galáxia internet: reflexões sobre internet, negócio e sociedade. Lisboa: Serviço de Educação e Bolsas/Fundação Calouste Gulbenkian, 2004.
} 
Ince ${ }^{4}$. A sólida e ciclópica análise feita, a partir de um locus privilegiado - Berkeley e o Silicon Valley —, ao fenómeno classificado, em 1973, por Daniel Bell, como «sociedade pós-industrial», deixa antever um futuro cheio de desafios complicados para a prática da História ciência, sobretudo a que incida sobre o «tempo mais recente», ou seja, sobre o processo histórico gerado sob a Era da Informação. A mudança do suporte técnico, destinado ao registo, quer dos actos e eventos mais simples e vulgares, inscritos no quotidiano das pessoas de não importa que classe, grupo, credo ou grau de instrução, quer dos mais solenes e mais decisivos para a vida colectiva dos cidadãos de países e continentes, tem uma consequência directa grave na forma como se passarão a preservar, ou não, as representações do tempo e do espaço, como se continuará a dar, ou não, espessura e durabilidade à memória individual e colectiva.

O quadro-síntese, com os principais desafios da Sociedade em Rede, incluído na conclusão da súmula possível de uma pesquisa, tão vasta e ambiciosa, é essencial para a reflexão despretensiosa, mas séria, que aqui pretendo deixar como praticante historiógrafo e como assumido cientista da informação. Vale, por isso, acompanhar o olhar optimista e, ao mesmo tempo, realista e lúcido lançado por Manuel Castells sobre a «expansão tecnológica» que envolve e absorve:

A Internet é, sem dúvida, uma tecnologia da liberdade, mas pode servir para libertar os poderosos e oprimir os desinformados e pode conduzir à exclusão dos desvalorizados pelos conquistadores do valor. Neste sentido geral, a sociedade não mudou muito. Porém, as nossas vidas não estão determinadas por verdades gerais e transcendentes, mas sim pelas maneiras concretas em que vivemos, trabalhamos, prosperamos, sofremos e sonhamos. Portanto, para sermos capazes de actuar sobre nós próprios, individual e colectivamente, e podermos aproveitar as maravilhas da tecnologia que criamos, encontrar um sentido para as nossas vidas, criar uma sociedade melhor e respeitar a natureza, devemos situar a nossa acção no contexto específico de dominação e libertação em que vivemos na sociedade em rede, construída em torno das redes de comunicação da internet ${ }^{5}$.

Castells alerta para uma evidência: o mundo está em processo de mudança baseado na tecnologia. Nesta base irreversível, que suscita de forma extremada ora entusiasmo, adesão e um encantamento utópico ${ }^{6}$, ora medo e animosidade pela exclusão social e económica, cultural e política, que a «sociedade em rede» pode trazer ou já se sente/teme que trouxe, expande-se o conceito de «espaço de fluxos», eixo crucial da análise sociológica do autor catalão e que serve para explicar as abundantes séries estatísticas, por ele usadas com solidez e desenvoltura, ou, tão só, alguns números dispostos ao correr da prosa e que bastam para impressionar e para reflectir:

\footnotetext{
${ }^{4}$ Castells, Manuel; INCE, Martin - Conversas com Manuel Castells. Porto: Campo das Letras, Editores, 2004.

5 CAstells, Manuel - A Galáxia internet, ob. cit., pp. 317-318.

6 Sobre o discurso utópico nos textos americanos "fundadores» da internet ver o estimulante trabalho de FliChY, Patrice - L'Imaginaire d'internet. Paris: Éditions La Découverte, 2001.
} 
A utilização da Internet como sistema de comunicação e como forma organizacional teve a sua explosão nos últimos anos do segundo milênio. Em finais de 1995, o primeiro ano da utilização generalizada da world wide web, havia cerca de 16 milhões de utilizadores das redes de comunicação informática em todo o mundo. No início de 2001, havia mais de 400 milhōes, as previsões mais fiáveis apontam para 1.000 milhões de utilizadores em 2005 e é provável que, até 2010, rondemos o número de 2.000 milhões, mesmo tendo em conta o abrandamento da sua difusão quando se entra no mundo da pobreza e do atraso tecnológico. A influência da internet transcende o número de utilizadores, pois o que interessa é a qualidade da utilização da rede. Actualmente, as principais actividades económicas, sociais, políticas e culturais de todo o planeta estão a estruturar-se através da Internet e de outras redes informáticas. De facto, a exclusão destas é uma das formas de exclusão mais grave que se pode sofrer na nossa economia e na nossa cultura ${ }^{7}$.

A rede preenche-se e constrói-se com milhōes de pessoas das mais variadas latitudes do planeta. Não há divisão possível por nações e por países ou estados, as línguas são múltiplas, mas o inglês impõe-se como a língua global, as actividades humanas e sociais de todo o tipo entram no "espaço dos fluxos» e desenvolvem-se aí de acordo com uma lógica de continuidade de práticas sociais, conhecidas no «mundo» real e presencial em carne e osso. No livro de conversas com Martin Ince, Castells não hesitou em tentar esclarecer melhor esse conceito-chave:

A parte de Nova Iorque que é global é uma parte muito maior do espaço de Nova Iorque do que o espaço global de La Paz, Bolívia. Mas La Paz também integra esta rede mundial com o seu pequeno centro de finanças e gestão. Portanto, o Espaço dos Fluxos é ao mesmo tempo um conceito abstracto e também uma construção muito material que liga lugares como nós de redes de instrumentalidade. Estes locais não são significativos por si mesmos, mas apenas como nós destas redes.

Tentei desenvolver uma análise similar para o espaço da indústria hightech, para os sistemas de informação, para a economia criminosa, e por aí fora. A rede é a mensagem no Espaço dos Fluxos. No total, este espaço de actividades dominantes tende a gerar um estilo de arquitectura, um certo tipo de estética cosmopolita e uma série de instalaçóes que caracteriza os estilos de vida da elite global. No entanto, o meu erro teórico foi o de assimilar a prática do Espaço dos Fluxos às elites globais e às suas actividades instrumentais, ao mesmo tempo que se opunha este ao espaço dos lugares onde a maioria das pessoas constrói o seu significado e vive as suas vidas. As actividades dominantes são de facto globais (da indústria de tecnologia de ponta aos mercados financeiros, da CNN ao tráfico de droga), como globais são as elites que desempenham a função de seus agentes. Mas o Espaço dos Fluxos é materialmente baseado nas novas tecnologias de comunicação. Assim, as pessoas de todos os tipos, desejando fazer todo o tipo de coisas, podem ocupar este Espaço dos Fluxos e usá-lo para os seus próprios propósitos ${ }^{8}$.

\footnotetext{
7 CASTELls, Manuel - A Galáxia internet, ob. cit., pp. 16-17.

${ }^{8}$ CASTells, Manuel; InCE, Martin - Conversas com Manuel Castells, ob. cit., pp. 67-68
} 
Ao esclarecer o conceito, simultaneamente abstracto/teórico e concreto/material ou materializado, Castells apresenta-nos a internet, ou o «espaço dos fluxos» aberto e «ocupado» não apenas pelas elites, mas por todos quantos desejem instalar-se e contribuir para a sua construção quotidiana e globalizada. E o que estamos assistindo, o que as estatísticas nacionais e dos organismos internacionais mostram é que, desde a esfera privada e íntima até à pública, estatal e supraestatal, a realidade construída e vivida, no dia a dia, invadiu e está a invadir de forma irreversível e expansiva as plataformas digitais, ou seja, a infra-estrutura das TIC onde a internet se localiza, tornando-se complemento e extensão natural do "espaço dos lugares».

\section{Real e Virtual ou do objecto da História...}

Virtual é um adjectivo, cujo significado tem de ser cuidadosamente examinado, que tem servido para sinalizar as actividades e as experiências concebidas no «universo web», em contraponto com o que acontece no planeta Terra fora da «rede». Começa, contudo, a ser bastante perceptível a impossibilidade de estabelecer uma divisória consistente entre o real e o virtual, assim como é inegável que o processo histórico em curso já se desenvolve no «interior» da Galáxia Internet e a História que venha a ser feita, discutida e ensinada, sobre o período balizado entre o último quartel do séc. XX e o último quartel do séc. XXI, não poderá ignorar, bem pelo contrário, todos os matizes desse processo e terá, desesperadamente, que obter informação, sempre contingente, parcelar e subjectiva, para reconstituir e interpretar o que se passou.

Os historiadores conhecem bem o debate que ao longo do séc. XX se desenvolveu e enraizou, no plano epistemológico, sobre a dificuldade em conhecer a realidade «encerrada» no passado. Estudá-la, descobri-la e compreendê-la a partir de traços e de vestígios vários que, quais peças de um incompleto puzzle, constituem a matéria-prima sine qua non do conhecimento histórico, é e continuará sendo o desafio maior do trabalho historiográfico, mesmo que, por efeito corrosivo do relativismo, tudo o que nos aparece como tendo acontecido, mais não seja que representações verossímeis individuais e colectivas e que, por isso mesmo, cabe no escopo de uma narrativa sugestiva e desenvolta, capaz de mesclar harmoniosamente a res factae com a res fictae 9 . Mesmo para os pós-modernistas e relativistas ${ }^{10}$, posicionados orgulhosamente nos

\footnotetext{
${ }^{9}$ Ver JAUSS, Hans-Robert - «Experiência histórica e ficção». In GADOFFRE, Gilbert (dir.) - Certezas e incertezas da História. Lisboa, Pensamento - Editores Livreiros, Lda, 1988, pp. 107-120.

${ }^{10}$ Por muito incómoda que a comparação seja e possa até parecer insultuosa, a concepção historiográfica relativista legitima o revisionismo histórico conhecido por negar a existência do Holocausto. O universo da res fictae contamina e domina remetendo para a esfera dos impossíveis a existência de res factae. Jauss no seu texto inspirador tentou pôr um equilíbrio hermenêutico capaz de estancar esse processo, afirmando a dado passo: O limite superior da experiência do mundo vivido pode estar situado no nível em que a experiência de si, sendo despersonalizada e o seu teor elevado à categoria de norma, pode ser objecto de uma dissertação exemplar. Este nivel de formação do sentido é familiar ao historiador: a experiência histórica formou-se a partir da tradição secular dos exempla, que também pouco se importam com estruturas do relato clássico. É sobre este ponto que se deve fazer oposição à "narratologia" hiper-atrofiada, que hoje conhecemos e que pretende, com A. Greimas, que a estrutura semântica de todas as dissertaçôes assenta na narração. Não se pode, em nenhum
} 
antípodas do positivismo ingénuo do séc. XIX, que conferiu ao documento um estatuto de absoluta veracidade, no mínimo, indefensável, a realidade é uma categoria presente, ainda que incómoda. Na Era da Informação, em que já estamos, a sua presença complexifica-se, e o adjectivo real já não convoca apenas, como antítese, o irreal ou ilusório (ficcional), mas o virtual, cuja significação está longe de ser simples e consensual. É, aliás, irresistível indagar como os relativistas encaram a (im)possibilidade da História, no interior da Internet, espaço de virtual(idade) e onde a realidade se confina, quando muito, à materialidade dos imprescindíveis equipamento informático e infraestrutura telemática (seja modem, banda larga por fibra óptica ou wi-fi...). Será que eles vêem, na Galáxia Internet, a confirmação plena de suas «teses»? E para os que acreditam na cientificidade da História, contrários, portanto, às posições relativistas e pós-modernistas, serão estes novos tempos um desafio promissor ou um convite impositivo a «baixar os braços», um convite à rendição aos ditames de uma ordem tecnológica nova e imprevisível? Estas perguntas desdobram a questão central da presente comunicação e conduzem a respectiva estratégia discursiva...

Pierre Lévy ${ }^{11}$, influenciado por Giles Deleuze, em especial pela leitura de Diferença e repetição (1968), afirmou entender a diferença entre possível e virtual: o primeiro tem a ver com o potencial que está preparado para acontecer sem alterações, e o segundo emerge quando a subjectividade humana entra no circuito. Mas, esta significação, dada por Lévy ao termo virtual, é demasiado singular e cola-se em demasia a Deleuze. Os informáticos e os comunicólogos trabalham (com) outro sentido que, aqui, interessa mais. Tomás Maldonado ${ }^{12}$ alerta-nos precisamente para esse outro sentido: Insomma, la realità virtuale (...) viene d'improvviso presa alla lettera, facendola diventare il centro di un programma di radicale agnosticismo e solipsismo filosofico ${ }^{13}$. Para Maldonado, virtual é sinônimo de ilusório, asserção encaixada num programa de pesquisa que tinha por objectivo indagar quais as implicações filosóficas, sociais e virtuais da realidade virtual. Percorrido o itinerário e atingido o objectivo, Maldonado tira suas conclusões e sintetiza, em forma de proposta, o seu pensamento:

Non mi sfugge, ma neppure mi preoccupa più di tanto, che questa asserzione possa essere giudicata come una mancanza d'interesse (e di curiosità) per le delizie dell'oltremondo. Confesso che l'idea del virtuale come técnica per «uscire dal mondo» mi risulta assolutamente estranea. Nell'orizzonte delle mie preferenze filosofiche non c'è posto per l'ipotesi che la realtà sia una spregevole illusione e che, illusione per illusione, sia meglio la realtà virtuale. Resto abbastanza fedele all'assunto - molto ingênuo, lo so - che la realtà esiste. Nobody is perfect ${ }^{14}$.

caso, fazer da narração a forma primária e universal da comunicação entre os homens, nem mesmo a matriz de toda a articulação de uma experiência histórica. Na medida em que é determinada pela totalidade (princípio, meio e fim da fábula) a narraçāo é historicamente precedida de uma gama de formas de comunicaçāo pré-literárias, definiveis por diversos modi discendi (citar, atestar, proclamar, convencer, demonstrar, etc.) (Ibidem, p. 116).

${ }^{11}$ LEVY, Pierre - Qu'est-ce que le virtuel? Paris, Édition La Découverte, 1995.

12 MALDONADO, Tomas - Reale e Virtuale, 2005.

13 Ibidem, pp. 145-146.

14 Ibidem, pp. 152-153. 
Contrapondo as conclusões do autor italiano à ambiguidade conceitual de Levy e aceitando, como consistente, a perspectiva de Castells de que as práticas sociais prolongam-se naturalmente no "espaço dos fluxos», vislumbra-se melhor o caminho a seguir por entre a antítese real versus virtual. E, para começar, pode-se entender o virtual não como antitético do real, mas, usando uma metáfora apropriada, a sua extensão em nível fenoménico diferenciado, ou seja, as sombras dos corpos ou dos objectos. As actividades virtuais têm, por trás, pessoas e grupos e tendem, por isso mesmo, a ser complementares, se não mesmo emulações da vida pessoal, familiar ou profissional e, nesta medida, o virtual significa o prolongamento do real, num condicionalismo tecnológico especial, uma vez que há uma dependência directa e decisiva da energia (electricidade) e da electrónica (informática e telemática). A falha destes factores paralisa o «espaço dos fluxos» e, consequentemente, afecta gravemente o mundo real: a economia, a política, a saúde, a segurança, a cultura, etc. dependem deles e já se inscrevem, cada vez mais, na Galáxia Internet, a ponto de precisarem que não haja «apagões», que não haja "vírus assassinos», que não haja avarias em provedores e servidores de "dados e de serviços on line»... A interdependência entre real e virtual é tão estreita que só faz sentido se pensarmos num continuum que a História terá de agarrar, embora fique difícil dizer, por antecipação, como ou com que estratégias heurísticas poderá fazê-lo.

Um exemplo ou caso, algo espectacular e talvez extremo, serve, aqui, para colocar o desafio aos artífices da História. Serve para saber se, na sua oficina, a matéria-prima do passado pode incluir «novos materiais» que reflectem a participação das pessoas, em plataformas digitais, para comunicarem umas com as outras — o e-mail é uma dessas formas comunicacionais assaz banal e se é certo que é possível descarregar as centenas de mails, recebidos no disco duro do computador pessoal, também é verdade que são imensos os serviços de correio electrónico disponíveis na web e nos respectivos servidores, onde fica armazenada a memória da correspondência sujeita a prazos de duração fixados livremente pelas empresas. A par do e-mail outras formas têm ganho milhares de aderentes, com especial incidência entre adolescentes e jovens, como são as pomposamente denominadas «redes sociais» (hi5, facebook, myspace, entre outras), onde acontecem encontros e trocas deliberadas de informação, nomeadamente fotográfica e musical, reveladora dos gostos, das preocupaçôes, das vivências desses estratos promissores da sociedade humana. Poderá a História perder o rastro digital dos nativos digitais que formarão a população cívica e politicamente activa num futuro não muito distante?

Mas, vamos ao exemplo ou caso provocatório, que pode, à primeira vista, parecer um jogo, porém, o seu criador, Philip Rosedale, declarou de modo lacónico e incisivo, em 2003, que o Second Life é uma nova vida e não um jogo.

O que é, então, o Second Life?

Desde logo, para os entusiastas da Tecno-utopia, o $S L$ está a ficar muito aquém do desejado, porque está demasiado igual ao que ocorre no espaço onde as pessoas de carne e osso vivem. Para os tecno-utopistas, expressōes como «realidade virtual» ${ }^{15}$ ou

15 Tenhamos presente uma breve cronologia que inclui o surgimento, pela primeira vez, desta expressão: 15000 A.C.: Os desenhos em cavernas em Lascaux mostravam imagens «virtuais» na escuridão da caverna, que iniciaram a idéia de aprimoramento do mundo real; 1849: Richard Wagner inicia a idéia das experiências 
«realidade aumentada» ${ }^{16}$ contrariam a radical crença no demiúrgico efeito da passagem deste mundo, em que vivemos insatisfeitos, para um "Mundo Novo», feito à medida do Ideal. O SL deveria, precisamente, configurar uma "nova vida», em vez de replicar e prolongar o real no virtual. A proposta do criador parece estar, assim, a ser desvirtuada pela criatura... Se entrarmos no $S L$, vemos uma sequência de figuras ou avatares acompanhados por palavras que anunciam tudo quanto se pode fazer nesse ambiente social de 3D que proporciona elevadíssimos níveis de interacção (fig. 1). Um ambiente social já previsto e dicionarizado por Gabriel Otman, em 1998, sob a designação de aldeia virtual:

Local aberto num mundo virtual onde os visitantes de todo o mundo podem encontrar-se anonimamente por intermédio de um avatar ao qual atribuem um nome de código e um papel.

Reconvertido à informática, Didier Tremblay anima de facto um site diferente dos outros [...] que conta a história de uma aldeia virtual, a Village Prologue, e dos seus 500 habitantes em meados do século $\mathrm{XIX}^{17}$.

E se prosseguirmos a exploração iniciática no $S L$ encontramos, de imediato, uma sugestiva página com a pergunta que o "cibernauta» deve formular e ver, sem demora, respondida - what is Second Life? (fig. 2). Entrando um pouco mais, deparamos um naipe de FAQ - Frequently Asked Questions (fig. 3), em que avulta a idéia de o SL ser uma construção dos residentes. As potencialidades desta "nova vida" fica nas mãos e na cabeça de quantos decidam aderir e construir, sem limites, o ambiente social que

em imersão utilizando um teatro escuro e envolvendo o público com imagens e sons; 1938: Konrad Zuse inventa o primeiro computador digital, conhecido como o Z1; 1948: Norbert Wiener cria a ciência conhecida como "cibernética», transmitindo mensagens entre homem e máquina; 1962: Morton Heilig cria um simulador de motocicleta chamado de Sensorama, com efeitos visuais, sonoros, vibraçôes e cheiros; 1966: Ivan Sutherland inventa capacetes para exibição de imagens, sugerindo uma janela para um mundo virtual;1975: Myron Krueger cria um laboratório de realidade virtual chamado «Videoplace», que permite o usuário interagir com elementos virtuais pela primeira vez; e 1989: Jaron Lanier inventa o termo «Realidade Virtual» e cria o primeiro comercial em torno de mundos virtuais.

16 Realidade Aumentada (RA) ou Ampliada (Tom Caudell cunha este termo, em 1990, enquanto estava na Boeing e ajudava trabalhadores a montar cabos em aeronaves) é uma linha de pesquisa dentro da ciência da computação que lida com integração do mundo real e elementos virtuais ou dados criados pelo computador. Atualmente, a maior parte das pesquisas em RA está ligada ao uso de vídeos transmitidos ao vivo, que são digitalmente processados e "ampliados» pela adição de gráficos criados pelo computador. Pesquisas avançadas incluem uso de rastreamento de dados em movimento, reconhecimento de marcadores confiáveis utilizando mecanismos de visão, e a construção de ambientes controlados contendo qualquer número de sensores e atuadores. A definição de Ronald Azuma sobre Realidade Aumentada é a descrição melhor aceita. Para Azuma, a RA é um ambiente que envolve tanto realidade virtual como elementos do mundo real, criando um ambiente misto em tempo real. Por exemplo, um usuário da RA pode utilizar óculos translúcidos, e através destes, ele poderia ver o mundo real, bem como imagens geradas por computador projetadas no mundo. Trata-se, pois, de um sistema que combina elementos virtuais com o ambiente real; é interativa e tem processamento em tempo real; e é concebida em três dimensões. Existem aplicações educacionais, jogos e aplicações de Realidade nas mais variadas áreas, como: bioengenharia, física ou geologia.

17 Otman, Gabriel - Dicionário da cibercultura. Lisboa: Instituto Piaget, 2001, p. 411. 
lhes é oferecido como uma virtual land em construção. Na resposta à questão Is Second Life a game (é o SL um jogo)? deparamos um sim e um não simultâneos, porque, por um lado, o interface e o dispositivo de animação são similares aos mais populares jogos online de múltiplos jogadores, mas, por outro, apresenta duas especiais diferenças:

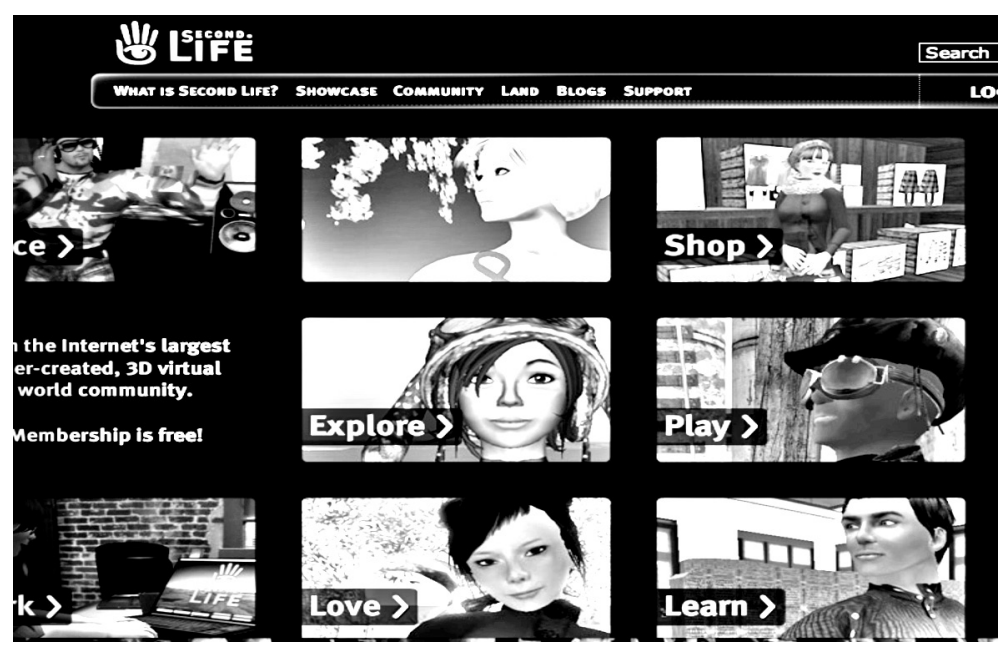

Fig. 1 - Primeira página do $S L$ (url:http://secondlife.com/)

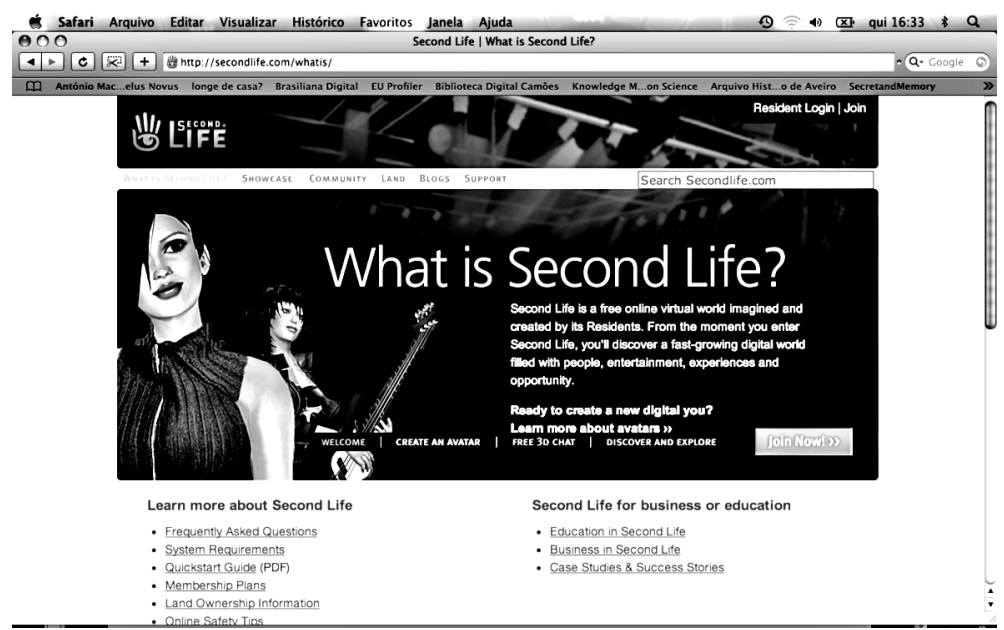

Fig. 2 - Página de introdução ao esclarecimento sobre o $S L$

(url:http://secondlife.com/whatis/) 


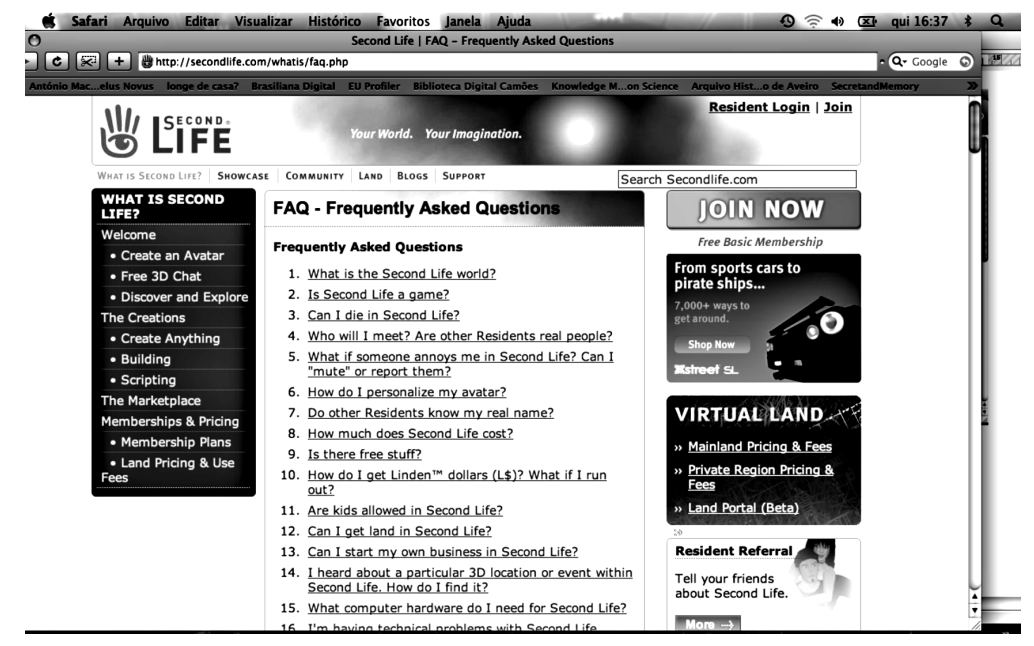

Fig. 3 - Página de entrada na Virtual land com «janela» das FAQ, ou seja, as perguntas mais frequentes e cuja resposta urge ser dada aos visitantes

a criatividade, ou seja, o SL virtual world provides almost unlimited freedom to its Residents, que o mesmo é dizer — este mundo é o que você fizer dele!; e o ser proprietário, ou seja, If you choose to get land to live, work and build on, you pay a monthly lease fee base don the amount of land you have. You also own anything you create - Residents retain intellectual property rights over their in-world creations ${ }^{18 .}$

Muitas outras perguntas estão seriadas e respondidas, tais como: "Posso morrer no $S L$ ?»; "Quem eu quero encontrar lá?»; "Existem pessoas reais no $S L$ ?» 19 ; "O que acontece se alguém me aborrece no SL? Posso "calá-lo" ou queixar-me dele?»; "Podem outros residentes conhecer o meu nome?»; "Como é que eu obtenho Linden dollar (L\$)?»...

Os esclarecimentos sucedem-se e a angariação de residentes, apesar de ter sofrido uma quebra acentuada por comparação com o boom inicial, já superou os 15 milhôes de pessoas. Entre elas há já uma percentagem significativa e crescente de "profissionais», isto é, de pessoas que ganham dinheiro real, obtendo, assim, no $S L$ receitas que lhes permitem viver e fazer despesas/consumo no mundo real. É, também, relevante sublinhar que não são apenas as pessoas que estão a aderir e a tornarem-se residentes do SL, mas também as instituições públicas e privadas: a Universidade do Porto já adquiriu uma «ilha» para fins de promoção e ensino; e a CNN ou a CBS estão

18 Ver http://secondlife.com/whatis/faq.php (acedido 26-7-2009).

${ }^{19}$ A resposta a esta pergunta é bastante precisa: SL é um mundo virtual com uma população residente de milhóes de pessoas provenientes de todas as partes do planeta. Cada pessoa é representada pelo seu avatar que corresponde à sua digital persona escolhida entre uma gama imensa de possibilidades: jogadores, esposas domesticas, artistas, músicos, programadores, advogados, bombeiros, activistas políticos, estudantes universitários, empresários, militares, arquitectos, médicos, etc. 
instalada no $S L$, bem como jornais e outras entidades da comunicação social que chegam a divulgar no mundo real ocorrências do mundo virtual.

Não pretendi ser exaustivo na análise do $S L$, apenas apresentar uma caracterização genérica que enquadre e fundamente o terceiro e último item. Este caso extremo obriga-nos a admitir que os ambientes e as redes sociais, em franca expansão, e que tenderão a envolver tantas mais pessoas quanto maior for o esforço dos governos e das empresas informáticas de combaterem a infoexclusão, alargando exponencialmente um espaço de participação digital e um mercado digital cobiçadíssimo, registam práticas sociais concretas de milhares de anónimos e de figuras com notoriedade que, em tese, devem ser captadas pelo olhar da História.

No entanto, a incerteza paira e adensa-se: Será que essas «vidas paralelas» deverão interessar à pesquisa e à escrita históricas? (Imagino, só a propósito desta pequena pergunta, um enorme e renhido debate...) Quem assegura a preservação dos registos electrónicos que correspondem a miríades de actos e de iniciativas nas mais diversas plataformas digitais? Cabe exclusivamente às empresas (e ao seu arbítrio estratégico) que criaram e asseguram a continuidade dessas redes e ambientes a salvaguarda dessa memória colectiva? Cabe aos Estados impor, através de legislação, a salvaguarda e protecção dos dados pessoais, que estando apenas no domínio privado podem ser transaccionados e usados para todo o tipo de fins, particularmente os perversos e criminais? Como poderão os historiadores vir a utilizar essa informação? Dar-se-á a eficaz conversão tecnológica e funcional dos Arquivos Nacionais e Públicos, vocacionados em geral para custodiarem informação estatal e privada (de diversas proveniências), em suporte electrónico/digital ${ }^{20}$ ?

Todas estas perguntas introduzem directamente o problema metodológico e a questão essencial do acesso a fontes variadas passíveis de serem analisadas e postas em confronto crítico. Indirectamente, emerge o problema epistemológico que é o das condições efectivas do conhecimento histórico, perspectivadas no quadro da Era da Informação em curso: Como é que será operacionalizada a aproximação historiográfica à realidade e à verdade possível por entre uma produção documental, muito diferente da tradicional em papel, uma produção imensamente mais volumosa, torrencial, mas incomparavelmente mais fácil de "falsificar»? Que recursos serão necessários para o historiador perseguir, amanhã e sempre, a "verdade histórica» diante de um continuum complexo que articula, de forma indissociável, o real ao virtual?

Muitas outras perguntas podem e devem ser formuladas, mas não se esperem respostas assertivas no último ponto deste texto. Limitar-me-ei a uma rápida revisitação da teoria da História, mas antes de me embrenhar nesse exercício oportuno e final, ocorre-me trazer à colação a proposta polémica e ingenuamente optimista de Francis Fukuyama, proclamando enfaticamente o "fim da História». Ele não estava, obviamente, a declarar o fim da ocorrência de acontecimentos, mesmo dos maiores e momentosos, mas da história compreendida como um processo singular, coerente $e$

20 Ver a este respeito o exaustivo levantamento dos projectos fortemente financiados por instâncias estatais e de organizaçôes internacionais, com vista à preservação digital da memória colectiva da Humanidade: PINTO, Maria Manuela Gomes de Azevedo - "Do «efêmero" ao "sistema de informação": a preservação na era digital». In Páginas a\&́b Arquivos \& Bibliotecas. Lisboa, 15 (2005), pp. 63-175. 
evolutivo, tendo em conta a experiência de todos os povos em todos os tempos ${ }^{21}$. Fukuyama "colou-se» ao filósofo idealista alemão G. W. F. Hegel e a Karl Marx, que tomara de empréstimo àquele o conceito de história e a concepção segundo a qual

a evolução das sociedades humanas não era ilimitada, mas que terminaria quando a humanidade conseguisse atingir uma forma de sociedade que satisfizesse as suas mais profundas e fundamentais aspiraçóes. Os dois pensadores postulavam, pois, um «fim da história»: para Hegel era o estado liberal, enquanto para Marx era uma sociedade comunista (...) Significava, outrossim, que não haveria mais progresso no desenvolvimento dos princípios e instituiçôes fundamentais, porque todas as questôes verdadeiramente importantes tinham sido resolvidas ${ }^{22}$.

No rescaldo da queda do muro de Berlim e da implosão da Guerra Fria, o autor americano elegeu o liberalismo e a democracia liberal como a etapa final da perfectibilidade humana, mas não prestou nenhuma atenção aos sinais perturbadores que vinham dos laboratórios e da indústria de ponta: a microinformática estava a nascer e a Galáxia Internet a formar-se, constituindo o elemento que faltava para atestar a emergência de uma nova Era e com ela um novo fôlego para a história em sentido hegeliano e um inusitado desafio para a História ciência. A revolução tecnológica trazia consigo um estímulo poderoso para a (re)invenção da actividade humana e outros desenvolvimentos técnico-científicos espectaculares, como os operados na biogenética e na nanotecnologia, que levaram já Alvin Toffler a admitir, numa entrevista, que a grande questão no milénio, em que entramos, será a de distinguir o humano do não humano. Em vez do «último homem» de Fukuyama parece que estamos perante um cenário potencial de metamorfose da Humanidade...

\section{O futuro (in)certo da História...}

A Nova História, surgida com o impulso fundador de Marc Bloch, Lucien Febvre e Fernand Braudel em torno dos Annales, instaurou um novo paradigma em contraposição à prática historiográfica erudita e crítica, robustecida ao longo do séc. XIX e apoiada na diplomática enquanto análise criteriosa do documento, pensado como fonte última da verdade... Ao impôr-se e ao expandir-se, insurgiu-se contra a evocação dos "grandes homens» ou das "grandes sínteses» e virou-se para as pessoas e para as mentalidades tanto no presente, como no passado, valorizando o quotidiano como espaço fértil e instância significadora da vida humana e social. No início do livro, que condensa o essencial da Mesa-Redonda subordinada ao tema A História - uma Paixão Nova e que reuniu expoentes máximos dessa «escola» francesa — Philippe Ariés, Michel de Certeau, Jacques Le Goff, Emmanuel Le Roy Ladurie e Paul Veyne - deparamos um enunciado breve dos fundamentos e dos objectivos desse olhar historiográfico renovado:

\footnotetext{
${ }^{21}$ FuKUYAMA, Francis - O Fim da história e o último homem. Lisboa: Gradiva, 1992, p. 14.

22 Ibidem, p. 14.
} 
Mas eis que surge uma nova História, nova inclusivamente em relação aos trabalhos de Fernand Braudel e à escola da revista "Annales».

Nova porque põe em causa o próprio lugar do observador, do historiador, que, como explicou muitíssimo bem Pierre Nora, já deixou de falar sob um ponto de vista absoluto - Deus, o progresso da Humanidade, a luta de classes - tendo, pelo contrário, de justificar a necessidade e a urgência dos seus trabalhos.

Nova também porque os objectos da História - Foucault é, a esse respeito, um exemplo bem marcante - mudaram. Da História dos grandes homens e das grandes sínteses, passou-se à História dos povos e das mentalidades, rica mas menos fácil de delimitar.

Esta renovação da História observa-se não só no estudo da época contemporânea - e a História do presente assinala uma revolução considerável - mas também na História antiga, na idéia que temos dos Hititas, dos Gregos e dos Romanos ${ }^{23}$

A marca deste movimento renovador foi profunda e ainda perdura, apesar de ter perdido fulgor e de terem crescido as críticas e os esforços de construir visões alternativas, merecendo inevitável destaque a apologia radical da História narrativa e da História política ${ }^{24}$. Pelo meio, entre os seguidores da admirada «herança» e os críticos ou cépticos, têm-se consolidado perspectivas sintéticas e matizadas que não negam a cientificidade da História, aceitam e revalorizam o seu posicionamento como ciência social, mas, ao mesmo tempo, reconhecem a força da narrativa e o peso da subjectividade na construção do conhecimento histórico. São, assim, limadas arestas e feitas aberturas, que evitem qualquer tentação quer de defesa dogmática do cientismo, quer da sua negação radical. Nesta linha intermédia e de síntese situam-se variados autores, de diversas latitudes geográficas e formaçōes, como, por exemplo, o estado unidense Georg G. Iggers ou o romeno Eugen Cizek. Aquele deixou a sua perspectiva evidenciada no final de um ensaio assaz útil e oportuno sobre a panorâmica internacional da cientificidade da História no séc. XX, sublinhando a dado passo:

Gracias a los trabajos de Le Goff, Braudel, Thompson y Koselleck somos hoy conscientes de lo condicionado que está, por la época y por la cual une el pasado, el presente y el furturo, es decir, el concepto del tiempo que, por así decirlo, constituía

${ }^{23}$ LE Goff, Jacques e outros - A Nova História. Lisboa, Edições 70, 1978, p. 11.

${ }^{24}$ Esta apologia faz-se através de uma desconstrução severa (Lawrence Stone destacou-se com um artigo publicado em 1979, The return of Narrative, reeditado em 1981 e em 1987) das ambiçôes científicas da Nova História: Dentro dos estritos limites exigidos por este propósito, e dentro deles somente, tenho inevitavelmente de fazer uma alusão crítica às ambições cientificas da Nova História. Os seus êxitos não carecem de ser louvados. São muitos, são grandes, estão à vista de todos e constituem um patrimônio historiográfico de inestimável valor. Mas tenho de falar do preço que custou porque, porventura inevitável, foi muito elevado. Importou nada menos do que na eliminação da história política e no consequente eclipse da narrativa, em favor de uma história do social inspirada por modelos, apoiada em quantificaçōes e servida por um discurso essencialmente analitico. Finalmente, com a terceira geração dos Annales formada nos anos $70 \mathrm{em}$ torno de um novo fôlego da história das mentalidades, acabou-se de minar a unidade da história em benefício de múltiplas histórias que não sabemos bem como ligar entre si (BONIFÁCIO, Maria de Fátima - Apologia da história política: estudos sobre o século XIX português. Lisboa, Quetzal Editores, 1999, p. 20). 
el hilo conductor para la historiografia moderna. Existen muchos tiempos, «el tiempo de la iglesia y el tiempo del comerciante en la edad Media», la longue durée de las estructuras sociales y culturales y el tiempo rápido de los acontecimientos; todas ellas concepciones del tiempo, que son condicionadas, al menos en parte, por los planteamientos del historiador y por el objeto de sus planteamientos. Se puede aseverar, con cierta justificación, que la historia no ha perdido, en modo alguno, su significado, sino que, gracias a la multiplicación de lãs perspectivas, ha ganado en significados.

(...) Esta panorâmica de la historiografia del siglo XX ha intentado mostrar que la creciente incertídumbre sobre la posibilidad de una historia «objetiva» no ha conducido al fin de una investigación histórica y de una historiografia científicas, antes bien a una mayor matización ${ }^{25}$

Seguindo outro caminho, Cizek chegou a uma posição de síntese idêntica com implicações metodológicas importantes:

Il est donc difficile, presque impossible, à l'historien d'attendre l'objectivité absolue. Car il est tenu, il est conditionné, par sa propre grille de lecture des phénomènes qu'il traite. Alors que cette grille est engendrée aussi bien par ses goûts personnels, que par la mentalité et les valeurs de sa propre époque. A notre avis, il peut être capable de transgresser cette grille de lecture, à condition de se mettre dans la "peau de ses personnages». C'est-à-dire s'il tache de penser comme pensaient les hommes qui peuplent la séquence historique qui l'intéresse, s'il recompose leurs valuers. Ce n'est qu'ainsi qu'il parvient à depasser un relativisme historique banal. L'historien à la fois prend conscience d'un certain relativisme: ce qui l'aide à le surmonter. Ainsi il se situe au niveau des phénomènes, des valeurs et des hommes, auxquels il a affaire. Ce n'est que comme cela qu'il acquiert une certaine impartialité et surtout la liberte. ${ }^{26}$

Em sintonia com estes alinhamentos epistemológicos, se pronunciara Reis Torgal, quase uma década antes, no livro de história da história, área, na altura, ainda muito pouco explorada em Portugal. Em História e Ideologia, logo no capítulo de abertura História, consciência histórica e ideologia encerra, em jeito de súmula das suas «teses» centrais, afirmando preferir a ideia de que a história é uma ciência, mas também uma "consciência", uma "memória", conceitos que dizem respeito, de forma mais ou menos complexa, à realidade ${ }^{27}$. A cientificidade da História coexiste com a presença constante e incontornável de ideologias que agem nela de forma mais simples ou complicada. Assumir esta evidência não significa «desvalorizar» a história ciência. Implica, pelo contrário, que ela seja assumida cientificamente, sem prejuizos ideológicos, mas também

25 IGGERS, Georg G. - La Ciência histórica en el siglo XX: las tendências actuales: una visión panorâmica y critica del debate internacional. Presentación, adaptación y revisión científica de Fernando Sánchez Marcos. Barcelona, Idea Books, S.A., 1998, p. 107.

26 CIZEK, Eugen - Essai sur une théorie de l'histoire. Bucuresti, Editura Universitatii din Bucuresti, 1998, pp. 166-167.

27 TORgAL, Luís Reis - História e ideologia. Coimbra, Livraria Minerva, 1989, p. 41. 
sem complexos "cientistas», e desejaríamos também que a "memória» de um povo se aproximasse o mais possivel da "objectividade» perseguida pelo conhecimento científico da história .

Assentemos, pois, nesta perspectiva epistemológica e partamos dela para antever a postura do historiador que, imerso na Era da Informação, se encarregará de a «reconstituir» e compreender mantendo vivo o património historiográfico da Nova História e os matizes correctores, que a foram posteriormente equilibrando e conciliando com as condiçôes e as limitações efectivas na construção do conhecimento histórico.

Calibrado por uma concepção da história «intermédia», o historiador, enquanto cientista social e apoiado no velho método «erudito-crítico» (constituído pelas três operaçôes-chave: a heurística, a crítica e a hermenêutica), terá à partida todas as condições para reafirmar a cientificidade do seu trabalho de pesquisa, mas os desafios e os obstáculos que o aguardam podem ser antevistos como enormes e muito complicados.

É já possível vislumbrar, num horizonte próximo, a momentosa questão heurística e que é uma questão metodológica bastante delicada. Mais importante e, sobretudo, mais difícil que o controlo ou vigilância crítica sobre a reconhecida subjectividade, ou permeabilidade ideológica do historiador/pesquisador, parece ser a análise perscrutadora da realidade através de uma "película» grossa, e bastante armadilhada, de «representações» acumuladas, através, em suma, da "documentação digital» com que o historiador se debaterá cada vez mais. Não estou a declarar que a informação, registada em papel, tem um fim à vista, embora seja, hoje, uma tendência clara, por parte dos Estados e entidades privadas, com responsabilidades na custódia e no acesso ao património arquivístico e bibliográfico, no sentido da digitalização de milhares e milhares de documentos em papel, para além de que a produção quotidiana de informação ocorre, acentuadamente, em suporte digital. Mas sendo a informação (entenda-se: conjunto estruturado de representações mentais e emocionais codificadas ...) a via sine qua non, pela qual o historiador formula os seus problemas de estudo, giza as suas hipóteses e busca todos os elementos que lhe permitam sustentar o seu exercício hermenêutico e escrever, de forma credível, acerca do que e como aconteceu, estou a postular a extraordinária dependência que a pesquisa histórica tem e terá de um excessivo caudal de fontes (o information overload não é uma miragem, é hoje um pesadelo bem real...) produzidas e presas a um suporte tecnológico radicalmente diverso do papel, que tem de ser dominado e entendido para que a análise crítica - essencial ao trabalho historiográfico - possa ser feita com êxito.

Estando o real plasmado no «universo» digital e sendo o real inseparável do virtual, como tentei mostrar nos pontos anteriores, o trabalho historiográfico não poderá deixar de interpelar a vida humana (e será, por acaso, um assomo de delírio ficcional associar a esta a vida dos robôs que a robótica e a inteligência artificial estão a «criar» em laboratórios espalhados pelo Mundo), desenrole-se ela, fora ou dentro, do «espaço dos fluxos». Poderá o historiador, daqui a umas décadas, a despeito dos modismos e da efemeridade possível (traço forte da Pós-Modernidade) dos ambientes e redes sociais, ignorar a actividade intensa de pessoas, grupos, organizaçôes e instituiçôes no Second Life? Acho que não pode, nem deve... Mas, o problema heurístico e crítico põe-se e com agudíssima acuidade. 
Como aceder à informação que permita desenvolver a pesquisa histórica? Como proceder à análise crítica que permita averiguar a autenticidade e veracidade dessas fontes? Sabendo nós, hoje, que muito do pensamento político, cultural, etc. se condensa em blogues, os quais se constituem referência obrigatória para a imprensa diária em papel e on line, blogues esses que levantam sérios problemas de credibilidade dos conteúdos divulgados e das fotografias expostas (a manipulação digital de imagens é, actualmente, uma prática banal e sofisticadíssima), não custa vê-los como fonte histórica no futuro, desafiando a capacidade crítica e hermenêutica dos historiadores.

Se muita da informação digital essencial ao trabalho historiográfico não puder estar (e não parece ser previsível que esteja), no domínio público e acessível de forma gratuita - as TIC, que acumulam informação, implicarão, para serem actualizadas e refrescadas ao ritmo da evolução futura do hardware e do software, despesas avultadas e que terão de ser suportadas pelos utilizadores e clientes —, como poderá o historiador atingir os seus objectivos de cientista social? Não está em causa a sua maturidade epistemológica para fazer ciência, mas a impossibilidade de, por um lado, obter «matéria-prima»e, por outro, de conseguir verificar a validade das fontes sem que seja informático...

É, para mim, óbvio que o historiador actual tem de ser e já é um info-incluído. Mas, a questão que deixo posta é outra, mais radical: o seu desempenho metodológico não o obrigará a adquirir sólidos conhecimentos de informática que lhe permitam, mesmo num registo interdisciplinar, submeter ao crivo da análise crítica fontes digitais «apócrifas» (perdoem-me o saboroso anacronismo)?

Sei que a diplomática contemporânea e autores como Luciana Duranti, com trabalhos e projectos situados no plano arquivístico e da preservação dos «documentos electrónicos», têm vindo a contribuir para que sejam encontradas soluções estáveis para que a História sobreviva, e a memória colectiva jamais se perca. Esse esforço meritório incide, porém, sobre a documentação governamental, a imprensa de âmbito nacional e internacional, as bibliotecas nacionais e públicas convertidas em bibliotecas digitais com funcionalidades inovadoras e pouco mais, deixando de fora uma imensidão de actores e de autores/produtores informacionais que não cuidarão de preservar a sua memória, partilhando-a com as empresas e serviços on line, onde, ou através dos quais, a produção e comunicação dos conteúdos fluem. Nessas circunstâncias a interrogação surge pertinente: quem e como conseguirá recuperar essa informação dispersa e "privatizada»?

Um historiador-biógrafo sabe que não pode prescindir da leitura atenta da correspondência diversa do seu biografado e dos coevos que, com ele, se entrecruzaram; acontece, porém, que a epistolografia em papel está a desaparecer e o mailing torna-se a regra. Mas, se os mails não forem descarregados no disco duro do computador pessoal (e se forem é preciso fazer backup's e transferências para equipamentos mais avançados, o que implica zelo e dispêndio de dinheiro), ficarão nos servidores das empresas, que prestam gratuitamente o serviço de correio electrónico, e essa informação toda fica sob sua custódia e presa ao destino incerto que elas terão (como poderá a lei proteger a salvaguarda da respectiva memória caso elas acabem e quem a guardará e possibilitará o acesso?). Este exemplo só, por si, é apelativo e perturbador... 
E este é só um exemplo, entre muitos que podem ser evocados e que caracterizam o complexo desafio posto à capacidade metodológica do historiador, no futuro que se aproxima. Exemplos que tendem a confirmar a tese da metamorfose da Humanidade: não estamos diante do "último homem», mas diante da emergência expansiva de um novo Homo que terá todo o direito à sua História.

Que História será essa?

Nesta comunicação só poderia chegar a este ponto. Ir mais além, sem correr o risco de leviandade futurológica, parece-me impossível. Por isso, por aqui me fico até que algum tempo mais me faça voltar às diversas pontas desgarradas deste texto e me bafeje com novo fôlego para retomá-las, ousando um pouquinho mais em direcção ao desconhecido... 
Série

Documentos

Imprensa da Universidade de Coimbra

Coimbra University Press

2010

- U

C • 